\title{
Anemia and performance status as prognostic markers in acute hypercapnic respiratory failure due to chronic obstructive pulmonary disease
}

This article was published in the following Dove Press journal:

International Journal of COPD

23 March 2013

Number of times this article has been viewed

\section{Helmy Haja Mydin \\ Stephen Murphy \\ Howell Clague \\ Kishore Sridharan \\ Ian K Taylor}

Department of Respiratory

Medicine, Sunderland Royal Infirmary,

Sunderland, United Kingdom
Correspondence: Helmy Haja Mydin Department of Respiratory Medicine, Aberdeen Royal Infirmary, Aberdeen AB25 IYX, UK

Tel +44 I22 4559442

Email helmy.hajamydin@nhs.net
Background: In patients with acute hypercapnic respiratory failure (AHRF) during exacerbations of COPD, mortality can be high despite noninvasive ventilation (NIV). For some, AHRF is terminal and NIV is inappropriate. However there is no definitive method of identifying patients who are unlikely to survive. The aim of this study was to identify factors associated with inpatient mortality from AHRF with respiratory acidosis due to COPD.

Methods: COPD patients presenting with AHRF and who were treated with NIV were studied prospectively. The forced expiratory volume in 1 second $\left(\mathrm{FEV}_{1}\right)$, World Health Organization performance status (WHO-PS), clinical observations, a composite physiological score (Early Warning Score), routine hematology and biochemistry, and arterial blood gases prior to commencing NIV, were recorded.

Results: In total, 65 patients were included for study, 29 males and 36 females, with a mean age of $71 \pm 10.5$ years. Inpatient mortality in the group was $33.8 \%$. Mortality at 30 days and 12 months after admission were $38.5 \%$ and $58.5 \%$, respectively. On univariate analysis, the variables associated with inpatient death were: WHO-PS $\geq 3$, long-term oxygen therapy, anemia, diastolic blood pressure $<70 \mathrm{mmHg}$, Early Warning Score $\geq 3$, severe acidosis $(\mathrm{pH}<7.20)$, and serum albumin $<35 \mathrm{~g} / \mathrm{L}$. On multivariate analysis, only anemia and WHO-PS $\geq 3$ were significant. The presence of both predicted $68 \%$ of inpatient deaths, with a specificity of $98 \%$.

Conclusion: WHO-PS $\geq 3$ and anemia are prognostic factors in AHRF with respiratory acidosis due to COPD. A combination of the two provides a simple method of identifying patients unlikely to benefit from NIV.

Keywords: acute exacerbations of COPD, noninvasive ventilation, emphysema, prognostic markers

\section{Background}

An estimated 3.7 million people in the UK have chronic obstructive pulmonary disease (COPD) ${ }^{1}$ with acute exacerbations of COPD (AECOPD) being the commonest cause for emergency medical admissions. Inpatient mortality rates can reach $25 \%$ and may be as high as $50 \%$ within 12 months of admission for AECOPD. ${ }^{2,3}$

Patients with acute hypercapnic respiratory failure (AHRF) and acidosis have the highest mortality rate and need for invasive mechanical ventilation (IMV). Several controlled clinical trials have shown that noninvasive ventilation (NIV) in AHRF significantly reduces both mortality and the need for IMV. ${ }^{4}$ Ward-based NIV is now standard practice in the management of AHRF in the UK, but mortality rate remains high. A recent UK national audit of COPD admissions reported inpatient and 90 -day mortality rates of $25 \%$ and $33 \%$, respectively, for patients receiving NIV. ${ }^{5}$ 
Furthermore, only $5 \%$ of patients with respiratory acidosis received IMV, and only $4 \%$ of those who died following NIV administration were given IMV.

This lack of escalation of care suggests that patient selection for NIV in clinical practice is problematic and needs improvement. Whilst IMV may be appropriate for some patients with severe acidosis, AHRF may be the terminal manifestation in a significant proportion. Identifying such patients would reduce futile interventions and enable timely introduction of palliative care.

Several prognostic indicators for patients admitted to hospital with AHRF due to AECOPD have been identified. These include age, severity of acidosis (particularly $\mathrm{pH}<7.25$ ), impaired consciousness, a high acute physiology and chronic health evaluation (APACHE) II score, hyperglycemia, and the development of concurrent nonrespiratory organ failure. ${ }^{2,6-11}$ Identification of high-risk patients may enable appropriate stratification of treatment, including NIV and IMV. However, identifying patients at the terminal stages of their disease is difficult and is usually a matter of clinical judgment.

In a previous study, we showed that performance status in combination with bedside physiological measurements from routine clinical assessment were highly predictive of mortality in patients admitted to hospital with AECOPD. ${ }^{12}$ The aim of this study was to identify factors associated with inpatient mortality for AHRF with respiratory acidosis due to COPD.

\section{Methods}

\section{Study design and patient population}

This prospective cohort study was performed in the Respiratory Unit at the Sunderland Royal Hospital, UK. Patients admitted and treated with NIV for AHRF due to AECOPD, between September 2009 and July 2010, were included if a diagnosis of COPD had been previously confirmed by clinical symptoms and spirometry. AECOPD was defined by the presence of two or more of the following features: worsening dyspnea, cough, increased sputum production, and change in sputum color. Exclusion criteria included: (1) a history of asthma, bronchiectasis or other concomitant respiratory diseases; (2) a diagnosis of advanced malignancy; and (3) pulmonary edema or pneumonia on admission.

All patients were given controlled oxygen therapy, corticosteroids, and nebulized bronchodilators. None required hemodynamic support with inotropes or vasopressors. NIV was initiated if there was evidence of
AHRF and acidosis $\left(\mathrm{pH}<7.35\right.$ and partial pressure of $\mathrm{CO}_{2}$ $\left(\mathrm{pCO}_{2}\right)>45 \mathrm{mmHg}$ ) on arterial blood gases (ABGs). NIV was delivered by nurses experienced in NIV, using bilevel positive airway pressure ventilators (BiPAP ${ }^{\circledR}$ Vision $^{\circledR}$; Royal Philips Electronics, Amsterdam, The Netherlands) with full face masks. Initial settings of inspiratory positive airways pressure (IPAP) and expiratory positive airways pressure (EPAP) were 12 and $4 \mathrm{~cm} \mathrm{H}_{2} 0$, respectively. IPAP was adjusted upwards by $2 \mathrm{~cm} \mathrm{H}_{2} \mathrm{O}$ increments according to the response and patient tolerance. Oxygen was entrained through the mask to maintain peripheral oxygen saturation $\left(\mathrm{SpO}_{2}\right)$ in the range of $88 \%-92 \%$. The response to NIV was assessed by ABGs between 1-2 hours after commencing treatment and as clinically indicated thereafter.

The end points of the study were inpatient mortality and mortality at 30 days and 12 months after admission.

\section{Data collection}

The severity of COPD was determined by the most recent spirometry reading taken when the patient was clinically stable. This was graded according to the Global Initiative for Chronic Obstructive Lung Disease (GOLD) staging classification. ${ }^{13}$ Other clinical data collected included the use of long-term oxygen therapy, number of hospital admissions for AECOPD in the preceding year, and previous documented episodes of AHRF. Patients' comorbidities were recorded and quantified using the index of Charlson et al. ${ }^{14}$

An assessment of patients' functional status was made using the World Health Organization performance status scale (WHO-PS) ( $0=$ Asymptomatic with normal activity; 1 = Symptomatic on physically strenuous activity but able to carry out work of a light or sedentary nature; 2 = Symptomatic: some limitation of normal activity but up and about $>50 \%$ of time during day, self-caring; 3 = Symptomatic: in bed/chair $>50 \%$ of time during the day, requires some help with self-care; and $4=$ Chair/Bedbound, cannot carry out any self-care). ${ }^{15}$

The Glasgow Coma Scale and a composite score of physiological impairment, the Early Warning Score (EWS), were recorded upon admission. ${ }^{16}$ The EWS is derived from heart rate, systolic blood pressure, respiratory rate, temperature, and AVPU score (consciousness level, based on patients' being alert, responding to voice, responding to pain, or being unresponsive) (Table 1).

Laboratory measurements included the worst (lowest $\mathrm{pH}$ ) ABGs prior to commencement of NIV, full blood count, albumin, urea, and C-reactive protein (CRP). 
Table I The Early Warning Score (EWS)

\begin{tabular}{|c|c|c|c|c|}
\hline Score & 0 & I & 2 & 3 \\
\hline $\begin{array}{l}\text { Heart rate } \\
\text { (beats per minute) }\end{array}$ & $51-100$ & $\begin{array}{l}40-50 \\
10 \mid-110\end{array}$ & $\begin{array}{l}<40 \\
1 \mid 1-130\end{array}$ & $>130$ \\
\hline $\begin{array}{l}\text { Systolic blood } \\
\text { pressure (mmHg) }\end{array}$ & $101-160$ & $\begin{array}{l}81-100 \\
16 \mid-200\end{array}$ & $\begin{array}{l}70-80 \\
>200\end{array}$ & $<70$ \\
\hline $\begin{array}{l}\text { Respiratory rate } \\
\text { (per minute) }\end{array}$ & $9-14$ & $15-20$ & $\begin{array}{l}<9 \\
21-30\end{array}$ & $>30$ \\
\hline $\begin{array}{l}\text { Temperature } \\
\text { (degrees celsius) }\end{array}$ & $36.1-37.5$ & $\begin{array}{l}35.0-36.0 \\
>37.5\end{array}$ & $<35$ & \\
\hline $\begin{array}{l}\text { Consciousness } \\
\text { level }\end{array}$ & Alert & $\begin{array}{l}\text { Responds } \\
\text { to voice }\end{array}$ & $\begin{array}{l}\text { Responds } \\
\text { to pain }\end{array}$ & Unresponsive \\
\hline
\end{tabular}

\section{Data analysis}

Data was analyzed using SPSS software (SPSS Inc, Chicago, IL, USA). Numeric data are presented as means and standard deviation (SD), unless otherwise stated. Continuous variables were compared by $t$-test and analysis of variance (ANOVA). A Chi-squared test was used to compare categorical variables in bivariate analysis. Receiver operating characteristic (ROC) analysis was used to identify the cutoff values for continuous variables significantly associated with mortality. Variables significant on univariate analysis $(P<0.05)$ were included in a stepwise (forward conditional) logistic regression analysis, and association with death was expressed as the odds ratio (OR) $(95 \%$ confidence interval). The 12-month survival was analyzed using the Kaplan-Meier method and groups compared by log rank test.

\section{Results}

There were 65 patients included ( $55 \%$ female) for study. The mean age was $71(10.5)$ years. The majority of patients had severe or very severe COPD. Over half $(57 \%)$ had at least one previous admission with AHRF. The overall inpatient mortality rate was $33.8 \%(22 / 65)$. Mortality was greater in males compared with females (41.4\% versus $27.8 \%$ ) but this was not statistically significant $(P=0.18)$. The mortality rates at 30 days and at 12 months after admission were $38.5 \%$ and $58.5 \%$, respectively.

Mortality was associated with the severity of COPD, longterm oxygen therapy use, and performance status (Table 2). Ninety-one percent of nonsurvivors had a WHO-PS $\geq 3$. The frequency of hospital admissions for AECOPD and previous episodes of AHRF were not associated with an increased risk of death. There was no difference in the severity of comorbidities between survivors and nonsurvivors.

Table 3 shows baseline physiological measurements and the EWS. Nonsurvivors had significantly greater perturbations of respiratory rate, diastolic blood pressure,
Table 2 Inpatient demographics, COPD severity, comorbidities, and performance status"

\begin{tabular}{|c|c|c|c|}
\hline & $\begin{array}{l}\text { Survived } \\
\text { inpatient } \\
\text { stay }(n=43)\end{array}$ & $\begin{array}{l}\text { Died as an } \\
\text { inpatient } \\
(n=22)\end{array}$ & \\
\hline Total & $66.2 \%(43 / 65)$ & $33.8 \%(22 / 65)$ & $P>0.05$ \\
\hline Male & $58.6 \%(17 / 29)$ & $41.4 \%(12 / 29)$ & \\
\hline Female & $72.2 \%(26 / 36)$ & $27.8 \%(10 / 36)$ & \\
\hline Age, years* & $69.6(9.5)$ & 74.1 (I.49) & $P>0.05$ \\
\hline $\mathrm{FEV}_{1}, \mathrm{~L} / \mathrm{s}$ & $0.78(0.38)$ & $0.51(0.26)$ & $P<0.05$ \\
\hline $\mathrm{FEV}_{1}$, \% predicted & $34.8(13.3)$ & $26.5(16.2)$ & $P<0.05$ \\
\hline \multicolumn{4}{|l|}{ GOLD stage } \\
\hline 2 & $13.9 \%$ & $5.3 \%$ & \\
\hline 3 & $18.6 \%$ & $15.7 \%$ & \\
\hline 4 & $67.4 \%$ & $78.9 \%$ & $P>0.05$ \\
\hline Admissions/year & $1.30(2.03)$ & 1.45 (I.47) & $P>0.05$ \\
\hline Previous AHRF & $55.8 \%$ & $59 \%$ & $P>0.05$ \\
\hline LTOT & $32.6 \%$ & $59 \%$ & $P<0.05$ \\
\hline Age adjusted $\mathrm{CCl}$ & $4.0(1.49)$ & $4.3(1.32)$ & $P=0.47$ \\
\hline \multicolumn{4}{|l|}{ Body mass index } \\
\hline$<18.5 \mathrm{Kg} / \mathrm{m}^{2}$ & $26.8 \%$ & $33.3 \%$ & $P>0.05$ \\
\hline $18.5-30 \mathrm{Kg} / \mathrm{m}^{2}$ & $53.6 \%$ & $47.6 \%$ & $P>0.05$ \\
\hline$>30 \mathrm{Kg} / \mathrm{m}^{2}$ & $19.5 \%$ & $19 \%$ & $P>0.05$ \\
\hline $\begin{array}{l}\text { Performance status } \\
\text { (WHO-PS) }\end{array}$ & $2(0-4)$ & $3(I-4)$ & $P<0.001$ \\
\hline WHO-PS $\geq 3$ & $21 \%$ & $91 \%$ & $P<0.0001$ \\
\hline
\end{tabular}

Note: *Expressed as mean (SD) and "expressed as median (range).

Abbreviations: AHRF, acute hypercapnic respiratory failure; $\mathrm{CCl}$, Charlson comorbidity index (Charlson et al, 1987); ${ }^{14}$ COPD, chronic obstructive pulmonary disease; $\mathrm{FEV}_{1}$, forced expiratory volume in I second; GOLD, global initiative for chronic obstructive lung disease; LTOT, long-term oxygen therapy; SD, standard deviation; WHO-PS, World Health Organization performance status.

and the Glasgow Coma Scale. Several laboratory variables were associated with increased inpatient mortality, including severity of acidosis and degree of hypercapnia (Table 4). Anemia and hypoalbuminemia were both associated with inpatient death. Urea was increased in $55.4 \%$ of cases but was not associated with mortality.

Dichotomous variables were determined as described above, for the WHO-PS score, EWS score, diastolic blood pressure, and $\mathrm{pH}$. The univariate analysis of variables associated with inpatient death is shown in Table 5 .

Table 3 Physiological measurements on admission

\begin{tabular}{llll}
\hline & $\begin{array}{l}\text { Survived } \\
\text { inpatient stay } \\
(\mathbf{n}=\mathbf{4 3})\end{array}$ & $\begin{array}{l}\text { Died as an } \\
\text { inpatient } \\
(\mathbf{n}=\mathbf{2 2})\end{array}$ & \\
\hline Heart Rate/minute & $100.0(21.7)$ & $I I 0.0(19.1)$ & $P=0.072$ \\
Respiratory Rate/minute & $25.9(7.2)$ & $31.2(8.9)$ & $P<0.05$ \\
BP systolic $(\mathrm{mmHg})$ & $140.4(25.8)$ & $127(26.6)$ & $P=0.06$ \\
BP diastolic $(\mathrm{mmHg})$ & $75.4(13.3)$ & $66.6(15.2)$ & $P<0.01$ \\
GCS & $14.4(I .3)$ & $13.1(2.8)$ & $P<0.05$ \\
EWS & $3.5(I .8)$ & $4.7(I .5)$ & $P<0.05$ \\
\hline
\end{tabular}

Abbreviations: BP, blood pressure; GCS, Glasgow Coma Scale; EWS, Early Warning Score. 
Table 4 Laboratory variables on admission

\begin{tabular}{|c|c|c|c|}
\hline & $\begin{array}{l}\text { Survived } \\
\text { inpatient stay } \\
(n=43)\end{array}$ & $\begin{array}{l}\text { Died as an } \\
\text { inpatient } \\
(n=22)\end{array}$ & \\
\hline $\mathrm{pH}$ prior to commencing & $7.24(0.07)$ & $7.19(0.08)$ & $P>0.05$ \\
\hline \multicolumn{4}{|l|}{ noninvasive ventilation } \\
\hline $\mathrm{pH}<7.26$ & $48.8 \%$ & $59 \%$ & $P>0.05$ \\
\hline $\mathrm{pH}<7.20$ & $16.3 \%$ & $45.5 \%$ & $P=0.014$ \\
\hline A-a gradient, $\mathrm{mmHg}$ & $78.8(168)$ & $46.3(138)$ & $P>0.05$ \\
\hline $\mathrm{pCO}_{2}, \mathrm{mmHg}$ & $82.9(23.6)$ & $98.5(32.6)$ & $P=0.030$ \\
\hline $\mathrm{Hb}, \mathrm{g} / \mathrm{dL}$ & $13.3(2.0)$ & II.5 (I.67) & $P<0.005$ \\
\hline Anemia & $27.9 \%$ & $68.2 \%$ & $P=0.002$ \\
\hline Albumin $\mathrm{g} / \mathrm{dL}$ & $37.1(4.2)$ & $34.8(4.1)$ & $P<0.05$ \\
\hline Hypoalbuminemia & $22 \%$ & $47.6 \%$ & $P<0.05$ \\
\hline Urea, $\mathrm{mmol} / \mathrm{L}$ & $8.9(5.1)$ & II.5 (8.8) & $P>0.05$ \\
\hline Urea $>7 \mathrm{mmol} / \mathrm{L}$ & $55.8 \%$ & $54.5 \%$ & $P>0.05$ \\
\hline CRP, mg/L & $94.5(120.2)$ & $163.8(150.1)$ & $P<0.05$ \\
\hline
\end{tabular}

Notes: Anemia was defined as $\mathrm{Hb}<13.0 \mathrm{~g} / \mathrm{dL}$ in males and $\mathrm{Hb}<11.5 \mathrm{~g} / \mathrm{dL}$ in females. Hypoalbuminemia was defined as albumin $<35 \mathrm{~g} / \mathrm{L}$.

Abbreviations: A-a, alveolar-arterial; CRP, C-reactive protein; $\mathrm{Hb}$, hemoglobin; $\mathrm{PCO}_{2}$, partial pressure of $\mathrm{CO}_{2}$.

Anemia was associated with increased in-hospital mortality, particularly in female patients: mortality if anemic was $57.1 \%$ vs $9.1 \%(P=0.003)$ for females and was $53.8 \%$ vs $31.3 \%(P=0.18)$ for males.

Multivariate analysis of factors associated with inpatient death showed that only WHO-PS $\geq 3$ (OR 39.0 [6.83-2 23.6]) $(P<0.0001)$ and anemia $(\mathrm{OR} 5.86$ [1.28-26.8]) $(P<0.03)$ were significant. The presence of both predicted $68 \%$ of inpatient deaths, with a specificity of $98 \%$. Figure 1 illustrates the effect of combining the WHO-PS and anemia on survival up to 12 months after hospital admission (log rank test $P<0.001$ ).

\section{Discussion}

In routine clinical practice, the mortality from AHRF with respiratory acidosis due to COPD is considerable despite

Table 5 Univariate analysis of variables associated with inpatient death

\begin{tabular}{|c|c|c|c|c|}
\hline & \multirow[t]{2}{*}{ OR } & \multicolumn{2}{|c|}{$\begin{array}{l}95 \% \text { confidence } \\
\text { interval }\end{array}$} & \multirow[t]{2}{*}{ Significance } \\
\hline & & Lower & Upper & \\
\hline WHO-PS $\geq 3$ & 37.7 & $7.4 I$ & 192.50 & $P<0.000 I$ \\
\hline $\begin{array}{l}\text { Long-term } \\
\text { oxygen therapy }\end{array}$ & 2.99 & 1.03 & 8.60 & $P<0.043$ \\
\hline Anemia & 5.54 & 1.81 & 16.92 & $P=0.003$ \\
\hline $\begin{array}{l}\text { Diastolic } \\
\mathrm{BP}<70 \mathrm{mmHg}\end{array}$ & 4.20 & 1.41 & $|2.5|$ & $P=0.010$ \\
\hline$E W S \geq 3$ & 11.25 & 1.37 & 92.02 & $P<0.024$ \\
\hline $\mathrm{pH}<7.20$ & 3.65 & 1.17 & 11.37 & $P<0.017$ \\
\hline Albumin $<35 \mathrm{~g} / \mathrm{L}$ & 3.23 & 1.04 & 10.02 & $P=0.042$ \\
\hline
\end{tabular}

Abbreviations: BP, blood pressure; EWS, Early Warning Score; OR, odds ratio; WHO-PS, World Health Organization performance status.

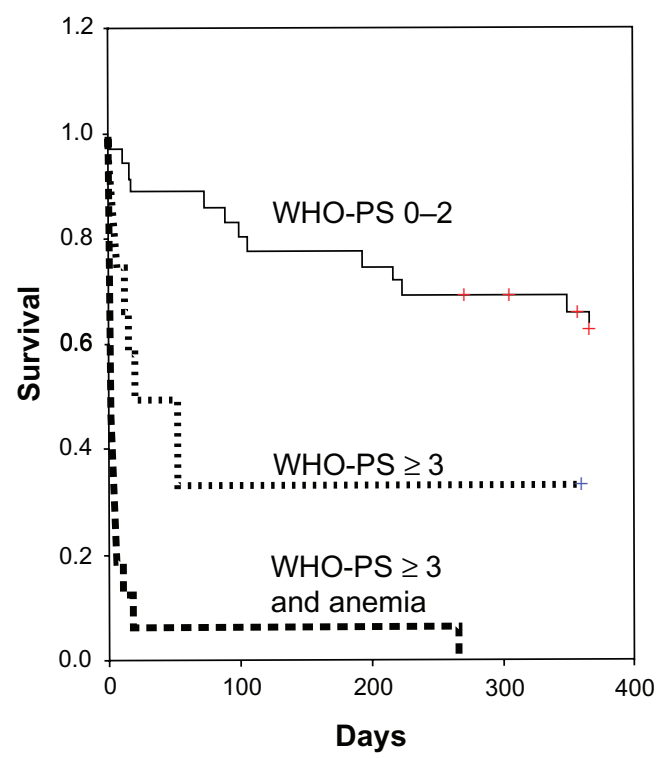

Figure I Kaplan-Meier curve of patient survival up to I year following hospital admission. The red crosses represent censored data.

Abbreviation: WHO-PS, World Health Organization performance status.

treatment with NIV. This study shows that patients who are unlikely to respond to NIV may be identified by a combination of poor performance status (WHO-PS $\geq 3$ ) and anemia.

The inpatient mortality rate in this study is comparable to that of the UK national COPD audit of patients receiving NIV (which showed an inpatient mortality rate of $25 \%$ ). ${ }^{5}$ In another study, comparing intensive care-delivered NIV with IMV, the inpatient mortality was similar (NIV 26\%). ${ }^{17}$ But these compare unfavorably with mortality rates observed in other studies of NIV for AHRF. ${ }^{8,9,11}$ In particular, the inpatient mortality in the YONIV study was only $10 \%$ for patients on NIV. ${ }^{8}$

The differences in mortality rates are probably a reflection of patient selection. Although the YONIV trial was described as a "real world" study, inclusion required $\mathrm{pH}$ in the range of 7.25-7.34. In the present study, $50.8 \%$ of our patients had $\mathrm{pH}<7.25$, similar to that of the UK national COPD audit. ${ }^{5}$ Patients in the studies of Chakrabarti et al ${ }^{9}$ and Confalonieri et $\mathrm{al}^{11}$ were also significantly less acidotic.

As with previous studies, inpatient mortality was associated with more severe acidosis on admission. However, $\mathrm{pH}$ was not independently predictive of inpatient death in our study. Similar observations were reported by Chakrabarti et al. ${ }^{9}$ One explanation may be that ABGs on admission do not necessarily reflect disease severity. Admission acidosis is often partly iatrogenic. Furthermore, some patients may initially respond to treatment, only to later deteriorate. ${ }^{18}$ In the UK national COPD audit, the highest mortality was seen in 
patients who were nonacidotic on admission but who became acidotic later. ${ }^{5}$ In a previous study, we showed that inpatient deaths from COPD exhibit a bimodal distribution, with early deaths (within 7 days of admission) being related to admission acidosis, whereas later deaths were not. ${ }^{12}$

Combinations of routine physiological observations have been shown to be of value in predicting survival for patients requiring NIV. One score chart, that includes the Glasgow Coma Scale, APACHE II score, respiratory rate, and $\mathrm{pH}$, identified patients at $>50 \%$ risk of NIV failure. ${ }^{11}$ In another study, a combination of baseline respiratory rate, random glucose, and admission APACHE II score was highly $(100 \%)$ predictive of NIV success. ${ }^{9}$ However, the APACHE II score is rarely used outside the intensive care unit, and a more straightforward assessment tool is required for routine clinical use.

Simple measurements of functional limitation alone may be more useful in this respect. In the present study, performance status was highly predictive of inpatient death (mortality if WHO-PS $\geq 3$ was $69 \%$ vs $5.6 \%$ ) and concurs with our previous observations. ${ }^{12}$ A UK COPD audit of outcomes for AECOPD showed that performance status was the best predictor of mortality (38\% if bed/chairbound vs $2 \%$ if normal activity). ${ }^{19}$ Morretti et al demonstrated that late NIV failure was associated with worse activities of daily living scores. ${ }^{18}$ Patients with a 6-minute walking distance of $<100 \mathrm{~m}$ have a 1 -year mortality of up to $60 \%{ }^{20}$ In the study by Chu et al, ${ }^{21}$ only the MRC dyspnea score was independently predictive of death.

Our observation that anemia is a significantly important predictor of inpatient mortality is also of particular interest. Although COPD is traditionally associated with polycythemia, the prognostic importance of anemia in this population is increasingly recognized. Cote et $\mathrm{al}^{22}$ demonstrated that anemic COPD patients had significantly shorter median survival (49 versus 74 months) compared with nonanemics. In a study of patients requiring IMV, the overall 90-day mortality among anemic COPD patients was $57.1 \%$ versus $25 \%$ for nonanemics. ${ }^{23}$ The mechanism of anemia in COPD and its impact on survival are unclear, but it has been suggested that the prognostic importance of COPD-related anemia may be its association with systemic inflammation in severe disease. ${ }^{24}$ There is increasing evidence of the importance of systemic inflammation in COPD. ${ }^{25}$ A relationship between mortality and the magnitude of CRP rise during exacerbations has been reported. ${ }^{12,26}$ Our findings in the present study, of an association between CRP level and death in AHRF due to COPD, were similar.
Patients with COPD that have frequent exacerbations have an increased risk of death. ${ }^{27}$ However, the frequency of admissions or previous episodes of AHRF were of no prognostic significance in this study. The presence of comorbidities is also of prognostic importance in COPD - in a study of 71,130 patients admitted to hospital with AECOPD, a Charlson score of 5 was associated with a fivefold increase in death in hospital. ${ }^{29}$ In our previous study, the Charlson score was significantly higher in patients that died, but it was not an independent predictor of mortality. ${ }^{12}$ It is therefore likely that the differences in performance status between survivors and those that died reflect COPD severity and its systemic effects rather than additional comorbidity.

Follow up of patients surviving an episode of AHRF requiring NIV indicates poor long-term prognosis. In this study, $37 \%$ of patients who survived admission died within 12 months. In a similar study of survivors of AHRF treated with NIV, 49\% had died within 12 months of discharge from hospital. ${ }^{21}$ Thus, the probability of medium-term survival needs to be considered prior to commencing NIV. The BODE Index, that comprises markers of disease severity in stable COPD, including forced expiratory volume in 1 second $\left(\mathrm{FEV}_{1}\right)$, body mass index, exercise capacity, and dyspnea, has been found to be helpful in predicting longterm prognosis. ${ }^{28}$ However a BODE score in the upper quartile is associated with a 12-month mortality of only $5 \%$ and is therefore of little utility in predicting short- to medium-term survival.

We acknowledge the limitations in this observational study from a single unit. However, we have controlled for potentially confounding variables through multivariate analysis. Many of our findings reflect the observations of other studies. We have deliberately included only variables that are measured in routine clinical practice and are therefore easily replicable and of potential clinical utility.

\section{Conclusion}

WHO-PS $\geq 3$ and anemia are prognostic factors in AHRF with respiratory acidosis due to COPD. A combination of the two provides a simple method of identifying patients unlikely to benefit from NIV. This study showed that mortality remained high despite treatment with NIV, a reflection of the fact that AHRF with respiratory acidosis can be a manifestation of the terminal stage of disease for patients with COPD. Whilst NIV is undoubtedly effective in the majority of patients with AHRF, a substantial proportion are subjected to a futile intervention that may be unpleasant and distressing, when end of life care may be more appropriate. Our study 
indicates that patients who are unlikely to respond to NIV may be identified by routine clinical assessment, but further studies are required to validate these findings.

\section{Authors' contributions}

All authors had full access to the original data and take responsibility for the integrity of the data and the accuracy of the analysis. HHM led the data collection, and SM led the data analysis. All authors made critical revisions and approved the final version of the submitted report.

\section{Disclosure}

The authors report no conflicts of interest in this work.

\section{References}

1. Shahab L, Jarvis MJ, Britton J, West R. Prevalence, diagnosis and relation to tobacco dependence of chronic obstructive pulmonary disease in a nationally representative population sample. Thorax. 2006;61(12): 1043-1047.

2. Connors AF Jr, Dawson NV, Thomas C, et al. Outcomes following acute exacerbation of severe chronic obstructive lung disease. The SUPPORT investigators (Study to Understand Prognoses and Preferences for Outcomes and Risks of Treatments). Am J Respir Crit Care Med. 1996;154(4 Pt 1):959-967.

3. Steer J, Gibson GJ, Bourke SC. Predicting outcomes following hospitalization for acute exacerbations of COPD. QJM. 2010;103(11): 817-829.

4. Ram FS, Picot J, Lightowler J, Wedzicha JA. Non-invasive positive pressure ventilation for treatment of respiratory failure due to exacerbations of chronic obstructive pulmonary disease [review]. Cochrane Database Syst Rev. 2004;3:CD004104.

5. Roberts CM, Stone RA, Buckingham RJ, Pursey NA, Lowe D; National Chronic Obstructive Pulmonary Disease Resources and Outcomes Project implementation group. Acidosis, non-invasive ventilation and mortality in hospitalised COPD exacerbations. Thorax. 2011;66(1):43-48.

6. Ucgun I, Metintas M, Moral H, Alatas F, Yildirim H, Erginel S. Predictors of hospital outcome and intubation in COPD patients admitted to the respiratory ICU for acute hypercapnic respiratory failure. Respir Med. 2006;100(1):66-74.

7. Afessa B, Morales IJ, Scanlon PD, Peters SG. Prognostic factors, clinical course, and hospital outcome of patients with chronic obstructive pulmonary disease admitted to an intensive care unit for acute respiratory failure. Crit Care Med. 2002;30(7):1610-1615.

8. Plant PK, Owen JL, Elliott MW. Early use of non-invasive ventilation for acute exacerbations of chronic obstructive pulmonary disease on general respiratory wards: a multicentre randomised controlled trial. Lancet. 2000;355(9219):1931-1935.

9. Chakrabarti B, Angus RM, Agarwal S, Lane S, Calverley PM. Hyperglycaemia as a predictor of outcome during non-invasive ventilation in decompensated COPD. Thorax. 2009;64(10):857-862.

10. Liu H, Zhang TT, Ye J. Analysis of risk factors for hospital mortality in patients with chronic obstructive pulmonary diseases requiring invasive mechanical ventilation. Chin Med J (Engl). 2007;120(4):287-293.
11. Confalonieri M, Garuti G, Cattaruzza MS, et al; Italian noninvasive positive pressure ventilation (NPPV) study group. A chart of failure risk for noninvasive ventilation in patients with COPD exacerbation. Eur Respir J. 2005;25(2):348-355.

12. Murphy SA, Haja Mydin H, Fatah S, Antunes G. Predicting end-of-life in patients with an exacerbation of COPD by routine clinical assessment. Respir Med. 2010;104(11):1668-1674.

13. Spirometry for Health Care Providers: Quick Guide. Global Initiative for Chronic Obstructive Lung Disease (GOLD). http://www.goldcopd. org. Accessed February 1, 2013.

14. Charlson ME, Pompei P, Ales KL, MacKenzie CR. A new method of classifying prognostic comorbidity in longitudinal studies: development and validation. J Chronic Dis. 1987;40(5):373-383.

15. Oken MM, Creech RH, Tormey DC, et al. Toxicity and response criteria of the Eastern Cooperative Oncology Group. Am J Clin Oncol. 1982;5(6):649-655.

16. Subbe CP, Kruger M, Rutherford P, Gemmel L. Validation of a modified Early Warning Score in medical admissions. QJM. 2001;94(10):521-526.

17. Conti G, Antonelli M, Navalesi P, et al. Noninvasive vs conventional mechanical ventilation in patients with chronic obstructive pulmonary disease after failure of medical treatment in the ward: a randomized trial. Intensive Care Med. 2002;28(12):1701-1707.

18. Moretti M, Cilione C, Tampieri A, Fracchia C, Marchioni A, Nava S. Incidence and causes of non-invasive mechanical ventilation failure after initial success. Thorax. 2000;55(10):819-825.

19. Roberts CM, Lowe D, Bucknall CE, Ryland I, Kelly Y, Pearson MG. Clinical audit indicators of outcome following admission to hospital with acute exacerbation of chronic obstructive pulmonary disease. Thorax. 2002;57(2):137-141.

20. Pinto-Plata VM, Cote C, Cabral H, Taylor J, Celli BR. The 6-min walk distance: change over time and value as a predictor of survival in severe COPD. Eur Respir J. 2004;23(1):28-33.

21. Chu CM, Chan VL, Lin AW, Wong IW, Leung WS, Lai CK. Readmission rates and life threatening events in COPD survivors treated with noninvasive ventilation for acute hypercapnic respiratory failure. Thorax. 2004;59(12):1020-1025.

22. Cote C, Zilberberg MD, Mody SH, Dordelly LJ, Celli B. Haemoglobin level and its clinical impact in a cohort of patients with COPD. Eur Respir J. 2007;29(5):923-929.

23. Rasmussen L, Christensen S, Lenler-Petersen P, Johnsen SP. Anemia and 90-day mortality in COPD patients requiring invasive mechanical ventilation. Clin Epidemiol. 2010;3:1-5.

24. Similowski T, Agustí A, MacNee W, Schönhofer B. The potential impact of anaemia of chronic disease in COPD. Eur Respir J. 2006;27(2):390-396.

25. Gan WQ, Man SF, Senthilselvan A, Sin DD. Association between chronic obstructive pulmonary disease and systemic inflammation: a systematic review and meta-analysis. Thorax. 2004;59(7):574-580.

26. Ruiz-González A, Lacasta D, Ibarz M, Martínez-Alonso M, Falguera M, Porcel JM. C-reactive protein and other predictors of poor outcome in patients hospitalized with exacerbations of chronic obstructive pulmonary disease. Respirology. 2008;13(7):1028-1033.

27. Soler-Cataluña JJ, Martínez-García MA, Román Sánchez P, Salcedo E, Navarro M, Ochando R. Severe acute exacerbations and mortality in patients with chronic obstructive pulmonary disease. Thorax. 2005;60(11):925-931.

28. Celli BR, Cote CG, Marin JM, et al. The body-mass index, airflow obstruction, dyspnea, and exercise capacity index in chronic obstructive pulmonary disease. N Engl J Med. 2004;350(10):1005-1012. 
International Journal of COPD

\section{Publish your work in this journal}

The International Journal of COPD is an international, peer-reviewed journal of therapeutics and pharmacology focusing on concise rapid reporting of clinical studies and reviews in COPD. Special focus is given to the pathophysiological processes underlying the disease, intervention programs, patient focused education, and self management protocols.

This journal is indexed on PubMed Central, MedLine and CAS. The manuscript management system is completely online and includes a very quick and fair peer-review system, which is all easy to use. Visit $\mathrm{http}: / /$ www.dovepress.com/testimonials.php to read real quotes from published authors.

Submit your manuscript here: http://www.dovepress.com/international-journal-of-copd-journal 